\title{
NET-ZERO EMISSIONS: MAIN TECHNOLOGICAL, GEOPOLITICAL AND ECONOMIC CONSEQUENCES OF THE NEW ENERGY SCENARIO
}

\author{
ANDREA SALERNO a, FRANSISCO SIMÕES ${ }^{b}$, ALESSANDRA RUFFINI $^{c}$ \\ a University of Milano-Bicocca, Department of Materials Science, Milano, Italy. MSc in Materials Science, a.salerno16@campus.unimib.it \\ b University of Coimbra, Department of Engineering, Coimbra, Portugal. MSc in Energy for Sustainability, francisco3@ua.pt \\ c University of Brescia, Department of Economics and Management, Brescia, Italy. PhD in Analytics for Economics and Management, \\ alessandra.ruffini@unibs.it
}

This review comes from a team group presented during "GEM 2021- Green Energy Management, Towards a sustainable energy transition". Summer School organized by the Department of Statistics and Quantitative Methods of University of Milano-Bicocca in 2021.

Keywords: energy transition, renewables, COP26, emissions, scenario, driving forces

\begin{abstract}
This paper discusses possible technical, economical and geopolitical consequences of the new energy scenario. We analyze the net zero emissions global race with an emphasis on the role renewable energies will play in this phenomenon and COP26's recent decisions on climate and energy transition. Using semiquantitative analysis method, the technological driving forces for future energy scenarios have been extrapolated. The technological developments and future scenarios regarding renewable energies are discussed comparing two different driving forces. Furthermore, there will be the discussion of possible geopolitical consequences due to fossil fuels trade depletion during energetic transition. Possible related consequences for MENA countries are investigated. In the last part there will be legal background analysis for electricity demand and renewable sources shift combined with techno-economical examples. Finally, considering all the contents, we drive our conclusions.
\end{abstract}

\section{INTRODUCTION}

This paper is structured into four sections. In the first part, the fundamental concepts linked with global race to net zero emissions are introduced, also providing some conclusions inherent to recent COP26 agreements. The role renewable energies will play in the challenge for emissions reduction is also illustrated in this section.

Second, technological developments and future scenarios regarding renewable resources are analyzed. Two different driving forces, obtained through Cross-Impact Matrix Multiplication Applied to Classification (MICMAC) analysis, are compared.

Third, possible geopolitical consequences relative to fossil fuels trade depletion have been investigated. Especially, consequences for the most involved Middle East and North Africa (MENA) countries are discussed. Additionally, the digitalization of energy sector and the related cyber security needs are presented.

In the fourth section, the analysis of policies and targets for electricity demand and renewable sources shift are investigated. A technoeconomical example based on new dynamic energy-economy system is also presented. In the last part, general conclusions are drawn regarding the whole ensemble incorporating the treated sectors.

\section{THE RACE TO NET-ZERO EMISSIONS}

In this part we will provide an answer to the following questions:

- what the race to net zero emissions is?

- which changes are needed?

- what role do renewable energies play in this scenario? 
- what hurdles do we face on the way to decarbonization?

The answers are necessary to provide the reader with basic knowledges helpful to understand the succeeding sections. These questions are answered mainly through the IEA document which indicates the most suitable efforts and crucial sectors to enable net-zero emissions. In addition, each answer is associated with a critical vision of the new COP26 result.

\subsection{What does net-zero emissions mean?}

International Energy Agency defines Net Zero Emissions as "a balance between anthropogenic emissions by sources and removals by sinks of greenhouse gases". ${ }^{1}$ Therefore, we not referring necessarily to the complete decarbonization but rather to compensation of anthropogenic greenhouse gas, GHG, emissions. Thus, the result can be reached creating GHG sinks to achieve an equilibrium between emission and absorption. Ongoing decarbonization is of course a crucial driving force in the race to net-zero emissions. The specific term "race", indeed, implies a specific urgency for the effort, which we believe is clear to everyone today.

In Figure $1^{1}$ is possible to observe all worldwide countries and their target year to become climate neutral or, in other words, emit net zero emissions. Notice that only two countries have already reached carbon neutrality: Bhutan and Suriname. They are very small countries with questionable government forms and poor population.

In general, however, the target year for many countries will change due to recent COP26 results. Indeed, increased widespread sensitivity on climate change and decarbonization surrounded all negotiations during the summit. Whether this resulted from a more realistic view or more pressing crowds is uncertain. What is certain are the promises, or blah blah blah as one known ecologist translate, for more ambitious plans and commitments from most of the developed world. Surely, for the first time, the mitigation targets for

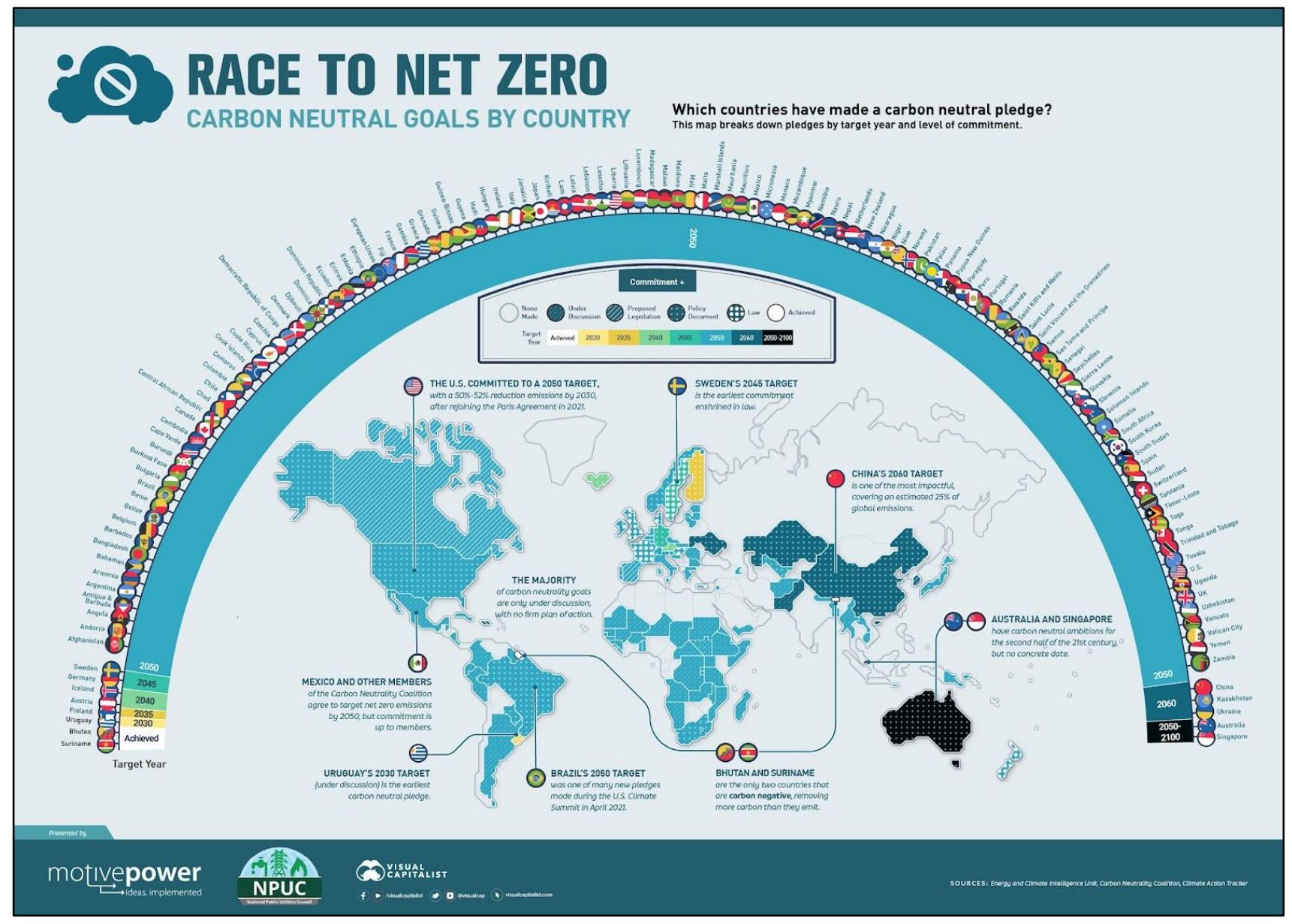

Figure 1 - Race to net zero emissions: country carbon neutral goals. (CIEA 
$1,5^{\circ} \mathrm{C}$ with respect to the preindustrial era is recognized. Thus, climate policies pledges by singular countries need to be updated and reinforced. Considering the current increase of $1,1^{\circ} \mathrm{C}$ the road to reach net zero-emission is still long but thanks to assured great efforts and shared responsibilities a glimmer of changes was observed.

\subsection{Which changes do we need?}

To reach net-zero emissions, we are not only talking about green electricity, even though it plays a major role. Various independent sectors need a shift in change. As a complete abandonment of fossil fuels is not likely reachable by 2050 even if $\mathrm{CO}_{2}$ prices keep rising, low-emissions fuels, like biofuels, biogas and hydrogen, will play a major role in areas where energy needs cannot easily, or economically, be met by electricity. ${ }^{2}$ Regarding the shift from fossil fuels to more sustainable sources of energy, COP26 has reached an historical target. There was the discussion of Article 6 from Paris Agreement (i.e., a shared international carbon market) but they also cited for the first time during an official summit the word coal. Words apart and relative rhetorical background from Indian prime minister, have been sketched the guidelines for cooperative approaches, rules and procedures of the shared carbon market mechanisms able to ensure that nationally determined contributions, NDCs, commitments can be executed.

The three main end-use sectors (transport, industry and building) need many advances to reach complete decarbonization.

Even though passenger travel and freight activity are expected to nearly double by 2050 the transport sector relies on policies that promote modal shifts and two major technology transitions. ${ }^{1}$ A transition towards electric mobility towards higher fuel blending ratios and a transition to use of low carbon fuels. It is expected that electricity will become the dominant fuel in the transport sector worldwide by 2040, but the dependency on fossil fuels is hard to completely overcome. ${ }^{3}$

As the second-largest global source of energy and $\mathrm{CO}_{2}$ emissions, industry is of significant relevance in achieving the net-zero goals. The big players are chemical, steel and cement industries accounting for over $60 \%$ of $\mathrm{CO} 2$ emissions. ${ }^{1}$ Hydrogen plays a central role in decarbonization because it helps to reduce emissions in some industrial processes. Although its relevance, today there are only pilot projects with microgrid structure and with hydrogen supply from renewable energy sources. In the building sector, energy efficiency and electrification are the two main drivers of decarbonization. Transition relay in technologies already available on the market: improved envelopes for new and existing buildings, heat pumps, energy-efficient appliances, bioclimatic and material-efficient building design. In addition, digitalization and smart controls will enable significant efficiency gains reducing a wide part of consumptions and relative emissions. Behavioral changes are also important to facilitate the decarbonization of electricity supply. Temperature settings for space heating and cooling, reducing excessive hot water temperatures, larger use of cold temperature clothes washing and line drying, are good and useful practices for the energetic transition. There is scope for these reductions to be rapidly and at no cost achieved.

It's clear that all these sectors individually are becoming more and more dependent on electricity. Thus, the need to generate green and sustainable electric energy is indispensable to decarbonize the whole energy supply chain and reach net-zero emissions.

\subsection{What is the role of renewable energies?}

Renewable energy sources are the key option for global decarbonization and a driving force in the race to net-zero emissions. Together with technological and structural innovations, renewable energy sources are pivotal for energetic transition in the numerous affected energy intensive sectors. Renewable energy sources allow to diversify and to decentralize energy generation while providing a more reliable supply of energy. Renewables offer a variety of sources that are more widely geographically distributed than hydrocarbons. Furthermore, they reduce local pollution and the GHG emissions caused by the transport and refining processes relate to fossil fuels.

Encouragingly, governments throughout Europe are stepping in to soften the blow of energy poverty. Energy efficiency policies can contribute to educate consumers, to improve the quality of homes, to reduce energy consumption levels and consequently lower energy poverty rates. In the 
last 20 years, the number of regulatory, financial, and education/information policies to promote household energy efficiency has increased sixfold. Countries that have actively promoted sustainable and long-term energy efficiency have seen energy poverty rates decrease and low-income households rely less on subsidies. Besides, energy poverty will be further reduced as energy efficiency improvements continue to progress, along with increased use of renewable energy. However, the financial goal for 2020 of 100 billion dollars for developing countries and those first affected by climate change has not been met yet. The promises for greater commitments in the future are useless and reflect the modus operandi used so far by rich countries. This is not only an unpleasant outcome of the COP26 but also the symbol of what is most feared: a further postponement in every field, starting from financial contributions. To move forward we must start making instead of making promises.

Furthermore, the ongoing shift to renewable energies and the improvements in technologies have the potential to lower the cost of transitioning out of fossil fuels. In the short term, this makes it more attractive to adopt more ambitious NDCs. In the long term, renewables provide the main technological means to eliminate global emissions, and this can help to shape the setting of long-term global temperature targets. With the hope that NCDs climate pledges reinforcement, set during COP26, will be converted in real acts.

\subsection{What hurdles do we face on the way?}

One problem in the fast-paced direct electrification of different sectors is the transfer of emissions up the energy supply chain. One example is the electrification of personal road transport with electric energy from traditional energy sources.

On the other hand, the heavy reliance on electricity also induces new vulnerabilities. The impact of electricity grid failures rises and cybersecurity is gaining more importance.

The possibility of effectively storing energy from renewable sources allows the 2050 carbon goals to be more realistic and reachable. This illustrates why current and future research and developments are indispensable for 2050 carbon goals. $^{2}$
Finally, cross-government approaches and solutions are crucial in the global race for net-zero emissions. Globalization connects different countries more than ever and the trans-border challenges of hindering climate change needs global and local communities to work together. COP26 has been the emblem of new shared awareness and responsibility. An indirect message that comes from the summit is the pivotal role of union and common interests because objectives are achievable only with collaboration. The common rules of the carbon market, the shared intentions of old polluting strategies phase-down, the aid to emerging and troubled countries are all symbols of unity and cohesion.

We, therefore, need not only a top-down strategy from powerful institutions or large sectors such as industry, transport and construction. The result of a bottom-up approach is also needed, achievable towards the transition to more renewable and sustainable everyday practices.

\section{TECHNOLOGICAL CONSEQUENCES OF ENERGY TRANSITION}

\subsection{Introduction and methods: driving forces using cross-impact analysis}

Scenario is a description of possible future situations and one of the most basic concepts of future studies. The analysis of the possible futures allows to understand in a deeper way our present and our choices to act in a strategic way. Driving forces for energetic scenarios are role players expected to reshape world energy future being the primarily responsible for the forecasts illustrated in the scenarios. Ghasemian et al identified different driving forces through semiquantitative foresight method which quantifies, through math principles, rational judgments of experts in various areas.

Applying cross-impact/structural analysis as a semiquantitative method and using the existing literature on global energy systems, 40 key factors, illustrated in figure 2, called drivers, are identified in different sectors. ${ }^{4}$

Second, the key factors were extracted using the Delphi method through questionnaires and interviews with 40 academic professionals, experts in international institutions (such as OPEC), and energy policymakers. Questions are based on the 
Social Technological Environmental-Economic Politic framework (STEEP framework). The Delphi method is used to fill a cross-impact matrix (CIM) by scanning possible futures. This allows to reduce uncertainties and investigates pairwise listed events. $^{4}$

In the final step, the impacts of key factors, listed in figure 2, on each other has been evaluated by Cross-Impact Matrix Multiplication Applied to Classification (MICMAC) analysis.

The result is a map illustrated in figure 3 which is divided into four quadrants, containing each one a variable type. Depending on the influence of a key factor in possible and its dependence from all the others in possible futures development we can distinguish autonomous variables, dependent variables, linkage variables and driving variables.

Driving forces represent all variables that can form future energy players individually. They have strong impacts on other key factors and are weakly affected by others.

They are expected to characterize a different future where unconventional resources, rapid technological development, renewables share in primary energy consumption, decarbonization plans, urbanization growth, climate changes are present. $^{4}$
Based on the results of this study, among technology key factors, the driving forces are:

- Technological developments in renewables (T1)

- Developments in the petroleum upstream sector (T2).

\subsection{T1: technological development in renewables}

Some predictions about the world share of renewable energies in total primary energy consumption are expected to increase from 9,5\% in 2015 to $63 \%$ in $2050 .^{5}$

As reported in many of the most popular future scenarios, like for example Shell scenarios and the one proposed by International Energy Agency, given the significant growth expectations of GDP (73\% and $89 \%$ in Shell scenario and IEA, respectively $)^{4}$ and economic prosperity in emerging economies, the energy demand in many sectors will experience an increasing trend. Thus, technological growth, high energy auditing and optimization potential would reduce the amount of energy consumed or would shift to less contaminating energy resources. Indeed, due to decarbonization and a shift to more efficient and lower energy-intensive technologies, we expect a

\begin{tabular}{|c|c|c|c|c|}
\hline Technological & \multicolumn{2}{|c|}{ Economic } & Environmental & Political \\
\hline $\begin{array}{c}\text { Technology development } \\
\text { in renewables (T1) }\end{array}$ & World GDP growth (E1) & $\begin{array}{c}\text { Global coal supply growth } \\
\text { (E9) }\end{array}$ & Climate change (C1) & Global governance (P1) \\
\hline $\begin{array}{c}\text { Tech development in } \\
\text { petroleum upstream (T2) }\end{array}$ & Energy efficiency (E2) & $\begin{array}{c}\text { Global renewable enrgy } \\
\text { supply growth (E10) }\end{array}$ & $\begin{array}{c}\text { Net carbon dioxide } \\
\text { emissions change }(\mathrm{C} 2)\end{array}$ & $\begin{array}{c}\text { National energy policies } \\
\text { (P2) }\end{array}$ \\
\hline $\begin{array}{c}\text { Tech development in } \\
\text { nuclear (T3) }\end{array}$ & $\begin{array}{c}\text { Infrastructural } \\
\text { investments (E3) }\end{array}$ & $\begin{array}{l}\text { Energy acces and poverty } \\
\text { (E11) }\end{array}$ & Land use and access (C3) & $\begin{array}{c}\text { Geo-political relations } \\
\text { and tensions (P3) }\end{array}$ \\
\hline Electric Vehicles (EV) & Financial shoks (E4) & $\begin{array}{l}\text { GDP per capita change } \\
\text { (E12) }\end{array}$ & Chemical pollution (C4) & Canging power blocs (P4) \\
\hline $\begin{array}{c}\text { Remaining technically } \\
\text { recoverable natural gas } \\
\text { source (T4) }\end{array}$ & $\begin{array}{c}\text { Emerging economies GDP } \\
\text { growth (E5) }\end{array}$ & Crude oil price (E13) & $\begin{array}{c}\text { Carbon capture and } \\
\text { storage (C5) }\end{array}$ & \\
\hline $\begin{array}{l}\text { Remaining technically } \\
\text { recoverable tight oil } \\
\text { resource (T5) }\end{array}$ & Consumer behavior (E6) & Natural gas price (E14) & & \\
\hline \begin{tabular}{|c|} 
Remaining technically \\
recoverable extra heavy \\
oil and bitumen resource \\
(T6)
\end{tabular} & $\begin{array}{l}\text { Global oil supply growth } \\
\text { (E7) }\end{array}$ & $\begin{array}{l}\text { US shale oil production } \\
\qquad(\mathrm{E} 15)\end{array}$ & & \\
\hline \multirow[t]{2}{*}{$\begin{array}{l}\text { Remaining technically } \\
\text { recoverable conventional } \\
\text { crude oil (T7) }\end{array}$} & $\begin{array}{c}\text { Global gas supply growth } \\
\text { (E8) }\end{array}$ & $\begin{array}{l}\text { Deep water shelf } \\
\text { production (E16) }\end{array}$ & & \\
\hline & & $\begin{array}{c}\text { Carbon dioxide price } \\
(\text { E17) } \\
\end{array}$ & & \\
\hline
\end{tabular}

Figure 2: 40 key factors of global energy scenarios derived from selected international studies, highlighted are the resulting driving force. Adapted from: Ghasemian, S. et al. An overview of global energy scenarios by 2040: identifying the driving forces using cross impact analysis method. 


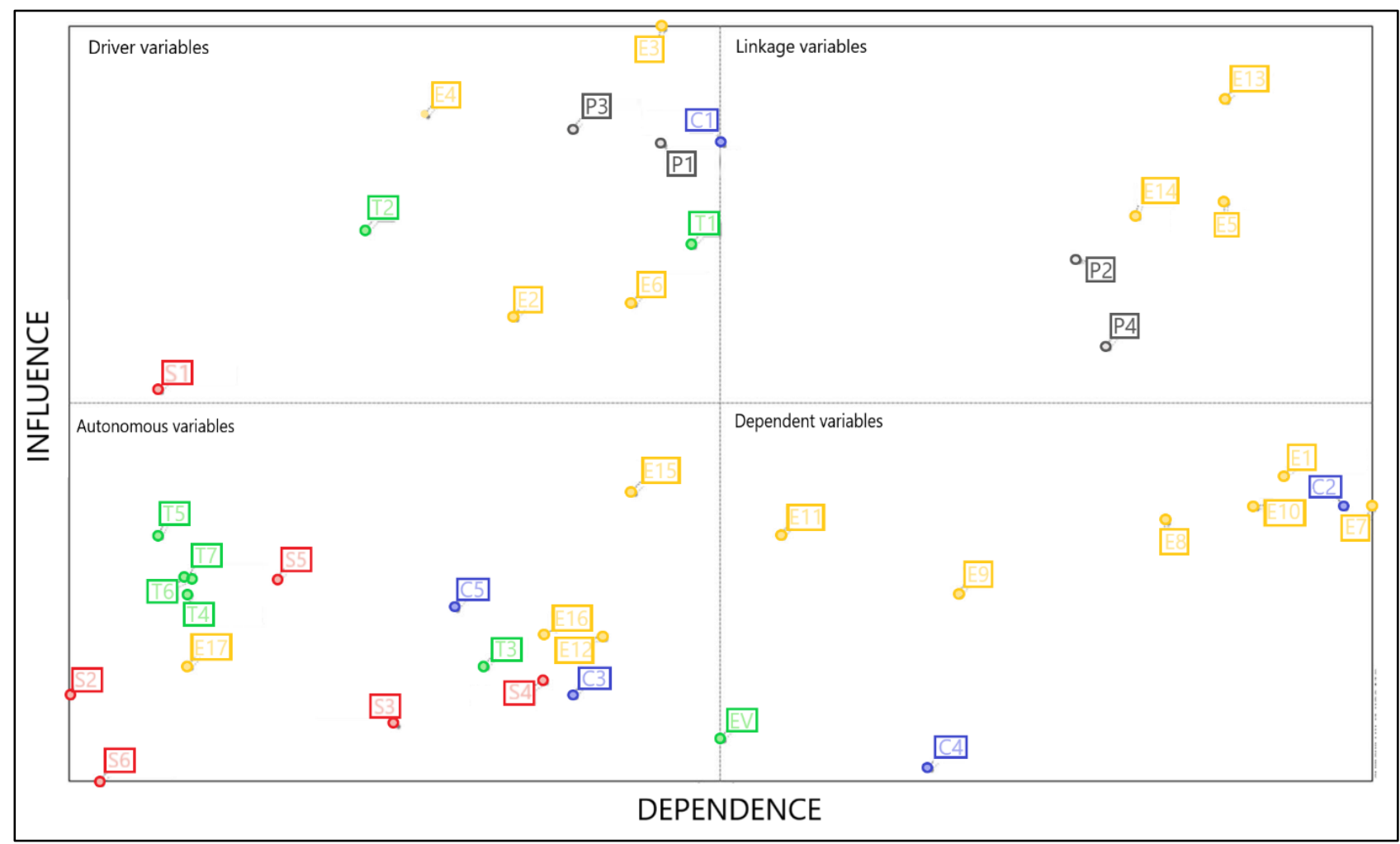

Figure 3: Potential direct influence/dependence map obtained through MICMAC analysis of the key factors. Adapted from: Ghasemian, S. et al. An overview of global energy scenarios by 2040: identifying the driving forces using cross-impact analysis method.

reduction in the energy consumption of power, transportation, industry and residential sectors. ${ }^{6}$

IRENA in its "Energy Transition Innovation" compares the current state of technological innovation in renewables with the innovation needs, given the 2050 objective of total net decarbonization. Based on this analysis, innovation bottlenecks are elaborated. As defined in previous chapter the sectors of industry, power, transport and buildings possess the greater emissions abatement potential and the greater impact on technological innovations.

The different technological opportunities by sector, analyzed by IRENA, identify several technologies that could play important roles in decarbonization. These technologies, in need for further developments for extensive use, are:

- Technologies able to ensure adequacy of supply and flexibility of variable renewable power in electricity systems. Seasonal storage systems, smart grids, market models and offgrid solutions.

- Advanced biofuels (from lignocellulosic feedstock and aromatics from lignin), biochemicals and biomaterials.
- New cement types able to reduce cement clinker needs: cement clinker production from limestone is a major cause of the $\mathrm{CO}_{2}$ emissions process.

- $\mathrm{CO}_{2}$ capture and storage (CCS) and/or use (CCSU) for industrial processes.

- Solar cooling, solar thermal and other renewable solutions for urban environments. These are well established but the roll-out is distributed across the world unevenly. Moreover, the current focus is on residential applications with integrated hybrid systems that, for example, combine solar heating with heat pumps of bioenergy.

By 2050, one-third of the energy save and emissions abatement would come mainly from four technology options: wind power, solar PV, electric vehicles for passenger transport and carbon capture and storage from industrial plastic processes. $^{5}$

\subsection{T2: technological development in petroleum upstream}


In general, the fossil fuel sector is one of the main culprits of greenhouse gas emissions. Global energy data are eloquent according to the World Energy Outlook 2019 of the International Energy Agency: in 2019 the total share of oil equivalent for renewables has more than doubled due to energy production in tons, while the share from wind and solar quadrupled to 254 Mtoe. $^{7}$ However, these gains do not seem to have a great effect. In 1979 nearly $84 \%$ of the world's demand for primary energy was met by fossil fuels and in 2019 the percentage did not change substantially. ${ }^{7}$ Most scenarios will not expect a significant change in the next 20 years, because of the increase in total energy demand by increasingly rapid industrialization and apart from emerging countries. $^{7}$

Ghasemian et al. in their analysis have found the GDP growth of emerging economies as one of the linking variables capable of generating a strong impact, in terms of influence, for future energy scenarios.

Sometimes, when innovations emerge on the market, they quickly overtake commodities and practices through market competition, a process that Joseph Schumpeter called "creative destruction". ${ }^{8}$ Behind the advancement of many other innovations, organizational actions lie. They serve to curb existing practices and dismantle regimes beyond the market. These actions can be translated in one word, exnovation: the intentional cessation of existing institutions, (infra)structures, technologies, products and practices. ${ }^{9}$ The spectacular rise of the automobile in the United States, for example, coincided with an equally spectacular fall of trams.

In the energy context, continued investment in innovation in renewable energy technologies is certainly justified. However, if left to the whims of creative destruction, renewables will not replace fossil fuels until such renewable energy technologies not only reach price parity with fossil fuels but also become so cheap that justify abandoning the extraordinary levels of irrecoverable costs that continue to be invested in the fossil fuel regime (e.g., the price for a single pipeline can be billions). ${ }^{10}$

Despite the efforts of renewable energy advocates, sometimes backed by supportive policies, they are faced with a pre-existing institutional regime to support the extraction and consumption of fossil fuels.
There is an urgent need for proportionate efforts in the exnovation of fossil fuel schemes.

The value of exnovation for organizations is clear: it describes adaption capacity involving strategies able to phase out policies and practices that have lost their effectiveness. Without exnovation new ideas and practices may not receive the needed support. Consequently, exnovation is an organizational resource entailing actions to unbalance preexistent institutional structures to replace them with new ones, more current. ${ }^{10}$

\subsection{Technological outcomes}

In conclusion, according to Ghasemian et al the path for energy transition, independently from the scenario, is still long. According to climate agreements, to reach net-zero emissions in 2050 the technology development is a powerful force able to drive policies, investments and costeffective changes.

In many sectors, a large variety of tech options need further developments that can lead to a more sustainable growth. The common opinion, derived from the different scenarios analyzed by Ghasemian and International Renewable Energy Agency (IRENA)'s Energy Transition Innovation paper is the following one: the change has to be put in place and this requires a great effort from a wide range of areas.

To foster the energy revolution, people's lifestyles and mindset need to change. All involved sectors must cooperate to generate a common feeling and a holistic approach to face the climate change problem and to support sustainable development and a circular economy. Studies on technologies aimed at using renewable sources to reduce climate change and to achieve the objectives set for 2050 are needed. At the same time, however, it is also necessary to promote the trend towards the decline of technological progress in the fossil fuel sector and the transfer of related funds to the innovation of sustainable technologies with a lower environmental impact. According to D. J. Davidson, the progress view is short-sighted and the innovation of new technologies based on renewable sources must be combined with the exnovation of fossil fuels old technologies.

A joint effort by the researchers and the ruling class as impulse and propellant is needed. 


\section{GEOPOLITICAL CONSEQUENCES OF ENERGY TRANSITION}

\subsection{Geopolitics and energy}

"Geopolitics is a deterministic causal relationship between geography and international affairs, focused on the permanent rivalry, territorial expansion and military strategies of imperial powers. With time, "geopolitics" came to denote the influence of geography on the power of states and international affairs more broadly, with less emphasis on determinism and more on the strategic importance of natural resources, their location, transportation routes, and chokepoints." ${ }^{\prime 11}$ (Tuathai, 1998)

For two centuries, the geographic concentration of oil, natural gas and coal reserves helped the international geopolitical landscape. Coal and steam power drove the Industrial Revolution which shaped geopolitics in the 19th century. Since then, control over the production and trade of oil has been a key feature of 20th-century power politics. A transition from fossil fuels to renewable energy to reduce greenhouse gas emissions in the atmosphere could transform global power relations no less than the historical shifts from wood to coal and from coal to oil.

According to IRENA's 2019 report renewable energy differs from fossil fuels in 4 aspects. ${ }^{12}$ Firstly, renewable energy is available in all countries in a variety of forms: solar, hydro, wind and biomass.

Secondly, renewable energies take the form of flows while fossil fuels are stocks.

Thirdly, the use of renewable energies allows decentralizing the production because this energy can be produced on either a large, medium or small scale.

Finally, renewable energy sources have marginal costs approaching zero, and with the progress of technology, the fixed costs for their installation have seen a continuous decrease. For example, the installation price of solar energy has dropped $60 \%$ in the last 10 years. ${ }^{12}$

\subsection{Geopolitics of renewables, the fossil fuels issues for MENA countries}

A consequence of energy transition will be a lower dependence on oil imports, which causes significant problems for the economies based on fossil fuel exportation.

According to Tagliapietra S., with the Paris agreement, the region most affected by the decarbonization will be the Middle East and North Africa (the so-called MENA countries). This region has half of the world's oil and gas reserves. In 2017 it was responsible for about $37 \%$ of oil and $22 \%$ of gas production worldwide. ${ }^{13}$ With energetic transition this region could lose between $25 \%$ and $40 \%$ of its revenues until $2040 .{ }^{14}$ Data presented by Tagliapietra S. in 2019 show that in this region hydrocarbon production is a major driver for Gross domestic product (GDP), tax revenues, exports, and the labour market. The countries that could be the most affected are Iraq, Kuwait, Saudi Arabia, Algeria and Qatar. If these economies do not diversify in their source of revenue, the decrease in fossil fuel exports could cause social instability and create political and social tensions in these regions.

Although there is a decrease in fossil dependence, the increase in renewable energy causes an increase in demand for rare metals that are used for their manufacture. However, the geopolitical impact on rare metals' demand increase will not be as significant as the current impact on the fossil fuel market. A study made by Månberger \& Johansson in 2019 shows that except for tellurium, copper and silicon, the concentration of rare metals is much higher than the concentration of oil. But their market economic value is much lower, being only 3 to $10 \%$ of the oil market value. ${ }^{15}$ In only 5 countries revenues from the sale of these metals are expected to increase by $5 \%$, and these countries are the Democratic Republic of Congo, Chile, Cuba, Madagascar, and Zambia. ${ }^{15}$

According to Overland I., another aspect to consider with the energy transition to renewables is the energy trade across borders. ${ }^{16}$ Energy trade between countries has always been used as a form of sanction by exporting countries. A study presented by Fischhendler et al. in 2017 shows that between 1938 and 2017 there were 38 cases of energy sanctions. ${ }^{17}$ Involved countries cut off fossil fuels supply but with renewable energy the trade between countries happens differently. When we 
talk about fossil fuels, the trade is unidirectional, from the exporting country to the importing country, but with renewable energy this trade is bidirectional. Since solar and wind energies are intermittent and till large-scale energy storage technologies are not yet developed, a country that produces energy excess can sell the surplus to its neighbours or, when in need, can purchase energy from them to keep balanced the energy grid.

With the energy transition, future energy sanctions will be based on the end of energy trade, but on the other hand, countries will be more interconnected with each other, which could make these types of sanctions unfeasible. ${ }^{17}$

\subsection{Energetic transition and digitalization}

Finally, the energy transition occurs at the same time as another important trend: digitalization. Digitalization has been transforming the energy sector making it more connected, intelligent, efficient, and more sustainable. However, the increasing complexity of digital systems for grid management can give rise to new cybersecurity challenges. ${ }^{16}$ The first case of a cyber-attack against a power grid took place in Ukraine in December 2015 and affected more than 230,000 people who were left without electricity for 6 hours. ${ }^{18}$

To avoid and solve rapidly these possible situations more investments in cybersecurity are needed: according to Mengidis et al. blockchain and $\mathrm{Al}$ technology are the most promising solutions. ${ }^{19}$

\section{ECONOMICAL CONSEQUENCES OF ENERGY TRANSITION}

\subsection{Economy in energetic transition and electricity sector}

The energy sector is under revolution because technological progress is revolutionizing how energy is produced and consumed, making the production based on fossil fuels no longer viable. Global, European and National institutions are supporting the development of sustainable energy policies through a policy framework that drives the transformation from fossil-based to zero-carbon. Globally, the targets set by COP21 with the Paris agreement (December 2015) aim at "holding the increase in global average temperature to well below $2^{\circ} \mathrm{C}$ above pre-industrial levels" pursuing "efforts to limit the temperature increase to $1.5^{\circ} \mathrm{C}^{\prime \prime}{ }^{20}$ In addition, from COP26 the admittance of urgent initiative opens the door to stronger pledges from national plans that must be shown in 2022.

Commitments of main signatories updated to COP21 are shown in the figure below (Figure 4).

At the European level, the European Commission has launched the European Union 2030 Climate and Energy Framework with 3 targets for decarbonization by 2030 :

1. To reduce $\mathrm{GHG}$ emissions by $40 \%$ with respect to 1990 levels;

2. To let renewable resources account for $32 \%$ in the final energy consumption;

3. To improve energy efficiency by $32,5 \% \cdot{ }^{20}$

Italy, therefore, has launched the National Energy and Climate Plan (PNEC) in December 2018 with its objectives: $40 \%, 30 \%$ and $43 \%$ respectively. ${ }^{20}$

The annual energy savings targets set between 01/01/2021 and 31/12/2030 are equivalent to a minimum of $0.8 \%{ }^{20}$ per year of the average final energy consumption of 2016, 2017, 2018.

The total primary energy demand is constantly increasing at an annual rate of $2,0 \%{ }^{20}$ since 2000 . To assure the reliable and secure provision of affordable energy, and the achievement of environmental goals at the same time, electricity is a central pillar in energy policymaking. The electric carrier has 7 features that make it pivotal for the energy transition:

1. It reduces $\mathrm{CO}_{2}$ emissions if electricity is generated through a balanced energy mix (this means that a significant share of renewables is required). The National and European renewable energy support policies, together with cost reduction, allowed to reach $+106 \%{ }^{20}$ of electricity, produced by renewable resources between 2005 and 2016. Also, it allows to reduce pollutant emissions improving air quality;

2. It limits noise pollution, stress and sleep disturbance: $68 \%^{20}$ of the population is expected to live in urban areas by 2050 . More 


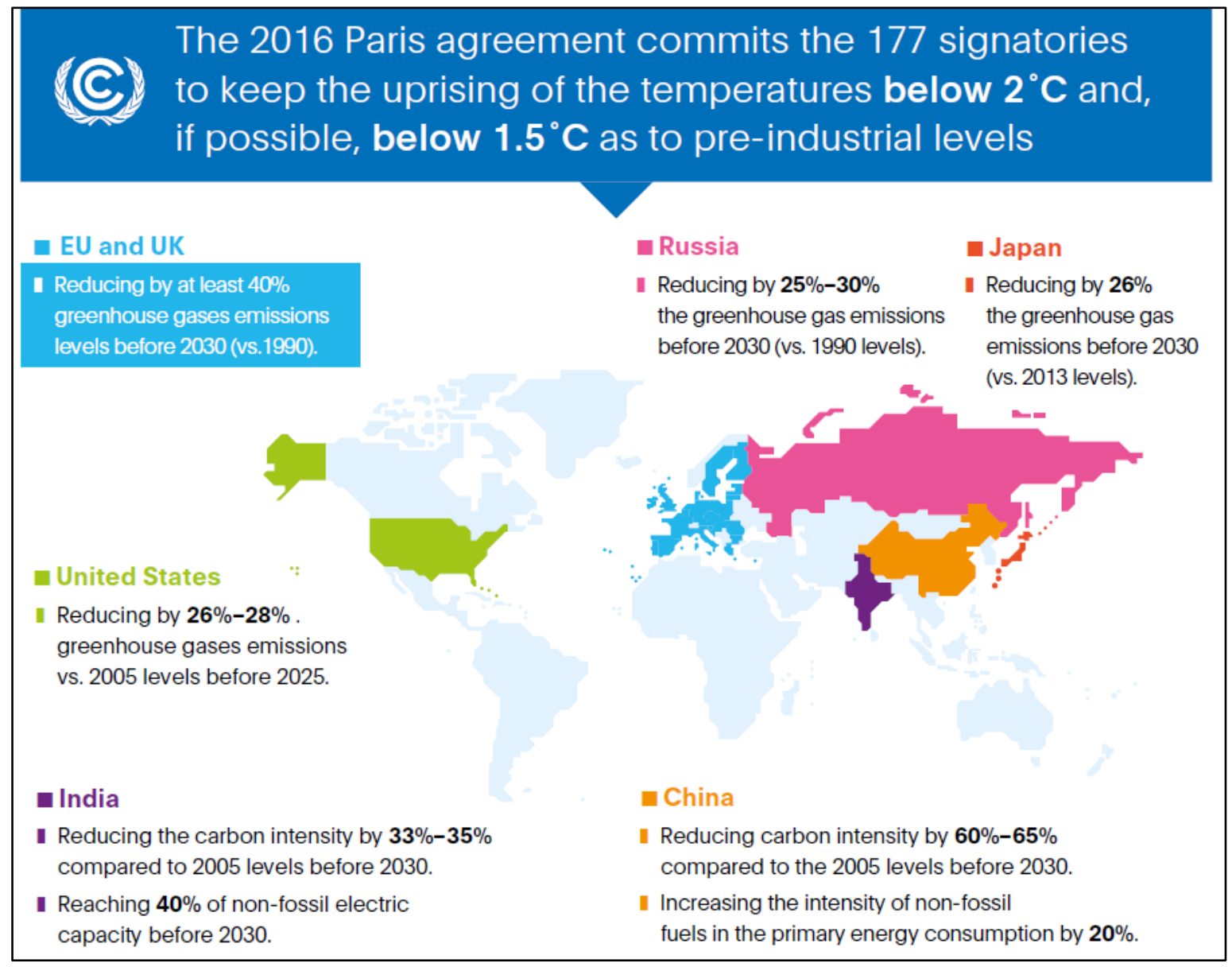

Figure 4: Transposition of COP21 goal by main countries worldwide. CENEL Foundation.

noise and light pollution will be generated and any instrument that allows to reduce them is relevant;

3. Thanks to its versatility, flexibility and integration with renewable resources, it improves the performance and the resilience of the energy system: traditional forms of energy, such as fossil fuels, require an input that needs to be transported through a pipeline, making the system more vulnerable to natural disasters. Given the growing share of renewables, electricity storage systems represent a pivotal element in both providing flexibility and supporting the renewable energy sources integration;

4. It provides a higher level of efficiency, reducing energy demand and GHG emissions. GDP growth has a negative correlation with electricity demand in developed economies: as the countries become richer, electricity demand decreases. In fact, over the last decade the correlation weakened significantly because of higher energy efficiency;

5. It can be easily integrated with digitalization: investments are expected to increase by $40 \%{ }^{20}$ by 2025 ;

6. It stimulates innovation and sustainability in lifestyles and industrial processes: the cost of renewables has gradually decreased over the last decade and for two years consecutively investments in the power sector reached 750 billion dollars, $48 \%{ }^{20}$ higher than those in the oil and gas sector;

7. It favours and supports the circular economy.

All these characteristics help the world to build a different kind of energy system which is based on 3 pillars: affordability, reliability and sustainability.

\subsection{Climate variability, energy policies and economic systems}

Considering what has been said about targets, economically speaking there has been a shift 
towards less energy-intensive sectors (such as commercial services sectors) which caused a decrease in energy intensity. Many instruments allow us to analyze and study what happens and where we are headed to.

An instrument is provided in the article published by Emodi et al (2019) where they studied the impact of climate variability and energy policies on the future energy system in Australia through the application of the LEAP system. ${ }^{21}$

It was developed by the Stockholm Environment Institute and it has been widely used since the late 1980s in public and private institutions.

This system (Figure 5) simulates an energy model where an accounting framework carries out an energy policy analysis of demand, supply and climate change mitigation assessment.

It also incorporates an environmental database (sourced from IPCC, the International Energy Agency, the US Department of Energy, the US Energy Information Administration and other academic publications) which describes technical characteristics, cost and environmental impacts of energy technologies. It can be linked to the Water Evaluation and Planning System for water-energy planning and it's useful to track environmental pollution at different stages of the fuel consumption chain.

\subsection{An example of techno-economic analysis in the energy-economy model}

We can also recall the model provided by Hafner et al (2021) who developed a new system dynamics energy-economy model: the Green Investment Barrier Model (GIBM), see Figure 6. It evaluates the UK's possible low-carbon electricity transition futures in terms of macro-economic and electricity system costs to answer two questions:

- What are the financial costs and the macroeconomic implications of a rapid electricity transition, which involves the immediate stop in using all currently still operating brown energy infrastructure?

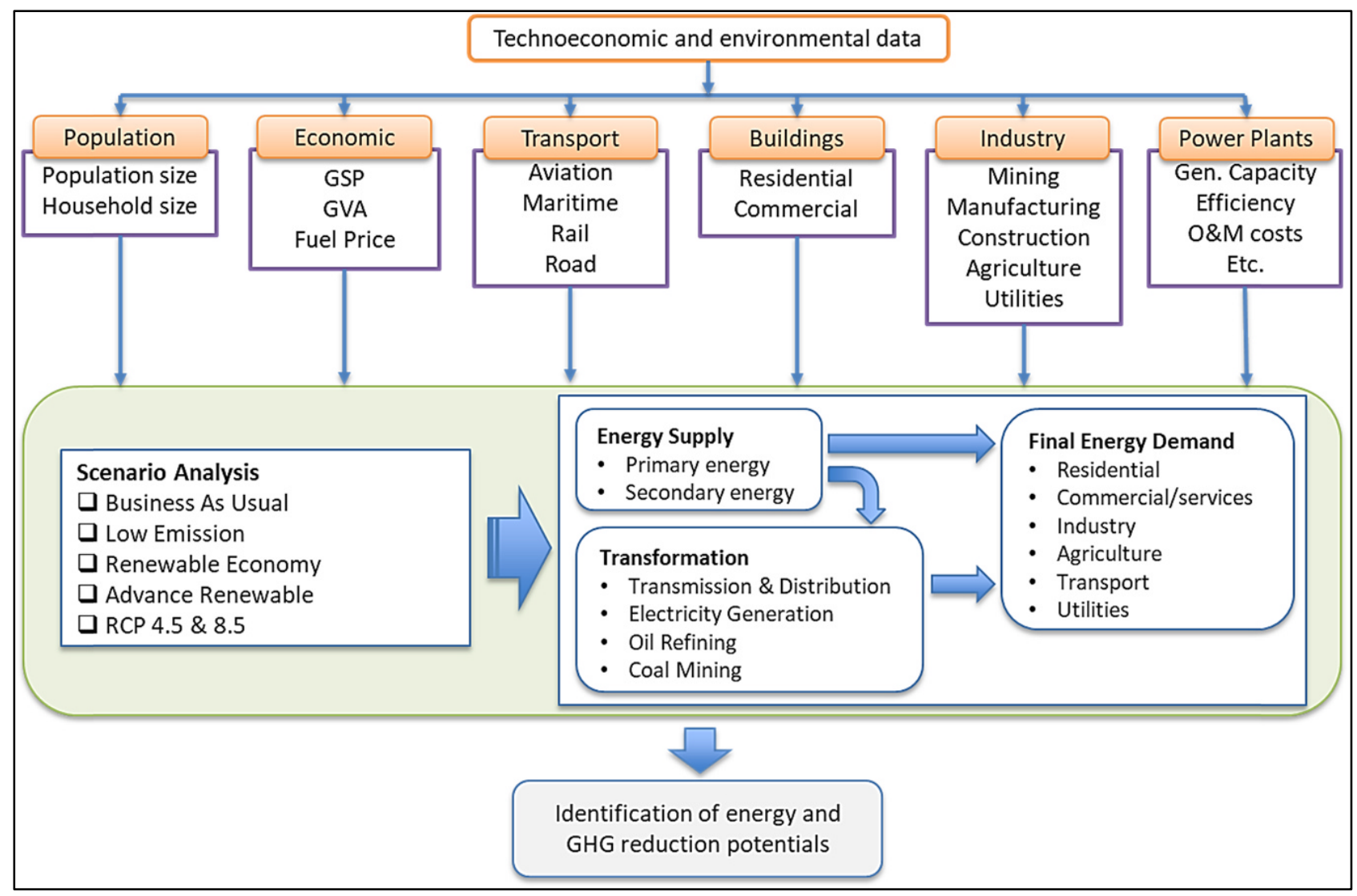

Figure 5: LEAP model structure. (CEmodi, N. V., Chaiechi, T. \& Alam Beg, A. B. M. R. A techno-economic and environmental assessment of long-term energy policies and climate variability impact on the energy system. Energy Policy 128, (2019). 


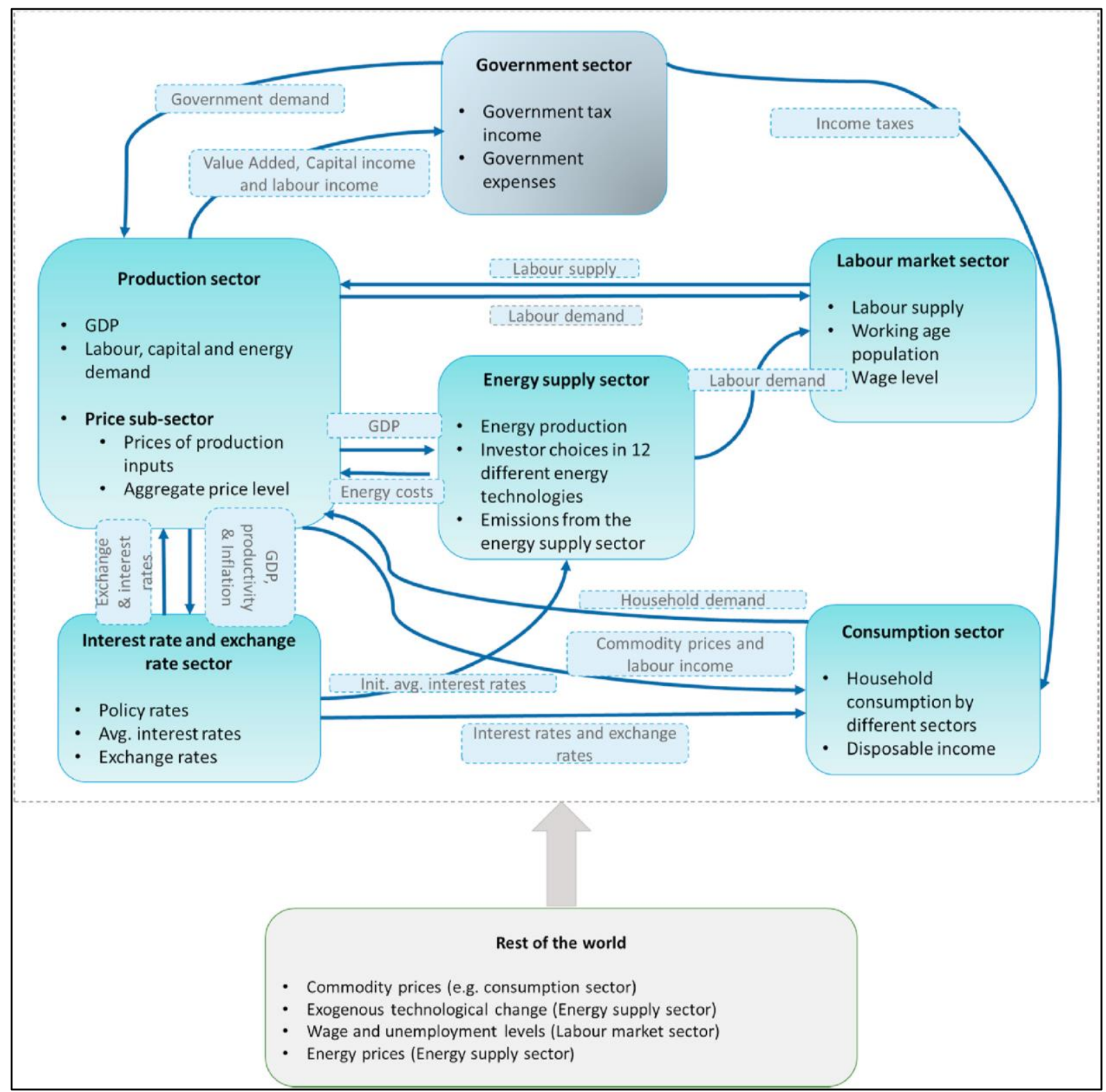

Figure 6: Overview of GIBM. (CHafner, S., Jones, A. \& Anger-Kraavi, A. Economic impacts of achieving a net-zero emissions target in the power sector. Journal of Cleaner Production 312, (2021).

- How are these results about less rapid lowcarbon electricity transition scenarios?

Hafner et al. (2021) simulated three scenarios: moderate, medium and fast. They concluded that:

- Moderate and medium scenarios have negative costs for emission reduction, while the rapid scenario costs around $390 \mathrm{f}$ per ton of reduced emissions. ${ }^{22}$ This means that a very fast transition, with the immediate shutdown of fossil fuel-based electricity infrastructure, is difficult in terms of managing the financial costs.
- Furthermore, in the first two scenarios GDP is lower than in the base-run. This is due mainly to renewable electricity infrastructure lower costs. Another reason is that in the base-run situation, investments in the most costefficient technology option is not guaranteed because it's influenced by behavioral factors, such as past decisions and risk-adversity. ${ }^{22}$

- However, all three scenarios show that transitions can be financially cost-effective thanks to decreasing costs and cost-efficient low-carbon electricity technologies. 
This brings us to the conclusion that the net-zero emission target in the power sector can be achieved cost-efficiently. ${ }^{22}$

\subsection{Economical outcomes}

Given the energy targets and the European Union full decarbonization objective in 2050, the future of energy should be fully renewable. However, also short-term decarbonization goals must be met; in this sense, other energy carriers can play an important role when combined with renewable electricity in the transition phase. Indeed, the exploitation of renewable and low-carbon gas can potentially accelerate the decarbonization effort in the short run. The rationale underpinning the interpretation is that natural gas, biomethane, biofuels and hydrogen can be used to increase sustainability and green production of energy and electricity as well.

\section{MAIN CONCLUSIONS}

In conclusion, the common opinion about energetic transition is one: the change has to be in place and this requires a great effort across a wide range of areas. To foster the energy revolution, lifestyle and mind set of people need to change. All involved sectors, transport, industry and building, must be cooperative, giving life to a common feeling and a holistic approach to problem of climate change, sustainable development and circular economy.

During the COP26 summit, national governors seem to have understood the problems inherent to climate change and the related necessary energy transition. Anyway, despite the concerns expressed, as for monetary aids to emerging countries, commitments and efforts are postponed to next year. It sounds coherent with the highlighted issues related to a not financially feasible fast transition. Additionally, is necessary to consider the extra related issues derived from current covid-19 pandemic conditions.

From a geopolitical view the energy transition would impact countries dependent on fossil fuels commerce, countries dependent on rare metals harvest and usage and it would also impact countries interconnections due to renewable energy trades. The field of cybersecurity related to digitalization of smart grid would be affected too, thus more investments are recommended To reach the net-zero emissions in 2050 according to climate agreements the technologies developments in general is a powerful driving force able to drag with it policies, investments and costeffective changes. At the same time, however, it is also necessary to promote the trend towards the decline of technological progress in the fossil fuel sector.

Additionally, funds towards the innovation of sustainable technologies with a lower environmental impact are necessary. Thus, as the techno-economic analysis reveals, the use of alternative vectors, even if $\mathrm{CO}_{2}$ emitters but derived from renewable sources such as biodiesel and biomethane, can represent a temporary solution and a valid way to differentiate exploitation. Indeed, as highlighted by various scenarios, a rapid change in paradigm for renewable sources usage. In general, for the quantity of required electricity, as it is essential for the achievement of the net-zero goal, cannot be feasible in terms of infrastructures and control systems.

The real question becomes now: do we have enough time to postpone actions? 


\section{REFERENCES}

1. IEA. Net Zero by 2050: A Roadmap for the Global Energy Sector. International Energy Agency (2021).

2. Milman, O., Chang, A. \& Kamal, R. The race to zero: can America reach net-zero emissions by 2050? The Guardian (2021).

3. International Energy Agency (IEA). World Energy Outlook 2019 - Analysis - IEA. World Energy Outlook 2019 (2019).

4. Ghasemian, S. et al. An overview of global energy scenarios by 2040: identifying the driving forces using cross-impact analysis method. International Journal of Environmental Science and Technology (2020) doi:10.1007/s13762-020-02738-5.

5. IRENA. REmap 2030 Full Report. /publications/2014/Jun/REmap-2030-Full-Report (2014).

6. IRENA. Renewable Energy Statistics 2017. International Renewable Energy Agency (2017).

7. IEA. Renewables 2019 - Analysis - IEA. International Energy Agency (2019).

8. Joseph A. Schumpeter, Capitalism, socialism, and democracy. in Cultural Policy Review of Books (2020). doi:10.4324/9781315872193-14.

9. Gross, M. \& Mautz, R. Renewable Energies. Renewable Energies (2014). doi: 10.4324/9780203798027.

10. Davidson, D. J. Exnovating for a renewable energy transition. Nature Energy vol. 4 (2019).

11. ÓTuathail, G. \& Dalby, S. Introduction: Rethinking geopolitics: towards a critical geopolitics. Rethinking geopolitics: towards a critical geopolitics (1998).

12. IRENA. Global Commission on the Geopolitics of Energy Transformation. http://www.geopoliticsofrenewables.org//media/Images/IRENA/GeoPolitics/Header/Goepolit ics_banner_final.jpg (2019).

13. International Energy Agency (IEA). The Oil and Gas Industry in Energy Transitions. The Oil and Gas Industry in Energy Transitions (2020).
14. Tagliapietra, S. The impact of the global energy transition on MENA oil and gas producers. Energy Strategy Reviews 26, (2019).

15. Månberger, A. \& Johansson, B. The geopolitics of metals and metalloids used for the renewable energy transition. Energy Strategy Reviews 26, (2019).

16. Overland, I. The geopolitics of renewable energy: Debunking four emerging myths. Energy Research and Social Science vol. 49 (2019).

17. Fischhendler, I., Herman, L. \& Maoz, N. The political economy of energy sanctions: Insights from a global outlook 1938-2017. Energy Research and Social Science 34, (2017).

18. Assante, M. Analysis of the Cyber Attack on the Ukrainian Power Grid. SANS Industrial Control Systems Security Blog (2016).

19. Mengidis, N., Tsikrika, T., Vrochidis, S. \& Kompatsiaris, I. Blockchain and AI for the Next Generation Energy Grids: Cybersecurity Challenges and Opportunities. Information \& Security: An International Journal 43, (2019).

20. Wang, Z. L. Triboelectric nanogenerators as new energy technology for self-powered systems and as active mechanical and chemical sensors. ACS Nano vol. 7 (2013).

21. Emodi, N. V., Chaiechi, T. \& Alam Beg, A. B. M. R. A techno-economic and environmental assessment of long-term energy policies and climate variability impact on the energy system. Energy Policy 128, (2019).

22. Hafner, S., Jones, A. \& Anger-Kraavi, A. Economic impacts of achieving a net-zero emissions target in the power sector. Journal of Cleaner Production 312, (2021). 